\title{
Pengaruh Aplikasi Refrigeran Hidrokarbon Terhadap Performansi Mobile Air Conditioning
}

\author{
Puji Saksono \\ Program Studi Teknik Mesin Fakultas Teknologi Industri Universitas Balikpapan \\ Jl. Pupuk Raya PO BOX 335 Balikpapan \\ Email : $\underline{\text { saksono_puji@yahoo.co.id }}$
}

\begin{abstract}
Refrigeration system this day has been developed fastly in advance technology manner. In general this system is developed to preserve food and to refresh the air condition. One of the usage of this system for Mobile Air Conditioning (MAC). The Global warming issues then become the limitation of the usage of refrigerant system of R-134a. As the replacement, retrofit process is conducted to change to refrigerant Hydrocarbon $(H C)$ type.

This research has objective to find the performance of those two types refrigerants. The test was conducted by using testing tool from MAC system that had been modified with control addition equipments.

The result of the test toward testing tool of Mobile Air Conditioning, the mass number of refrigerant in full level condition of $\mathrm{HC}-134$ is less than $\mathrm{R}-134 \mathrm{a}$. The mass of $\mathrm{R}-134$ a was 420 gram while HC-134 was 240 gram. Beside the usage of refrigerant is lesser than normal condition, the aplication of HC-134 can give coeffcient of performance (COP) higher value than $R-134 a$.
\end{abstract}

Keywords: refrigerant type, refrigeratIon effect, compression work, COP

\section{Abstrak}

System pendingin pada saat ini telah banyak berkembang pesat seiring dengan kemajuan teknologi. Pada umumnya sistem ini digunakan untuk mengawetkan makanan dan penyegaran udara. Salah satu pemanfaatannya yaitu pada Mobile Air Conditioning (MAC). Isu pemanasan global di bumi menjadi bagian pembatasan pemakaian refrigeran $R-134 a$, dan sebagai gantinya dilakukan retrofit ke jenis refrigeran Hydrocarbon (HC).

Penelitian ini bertujuan untuk mengetahui performansi dari kedua jenis refrigeran tersebut. Pengujian dilakukan dengan menggunakan alat uji dari sistem MAC yang telah dimodifikasi dengan peralatan kontrol.

Hasil pengujian pada alat uji Mobile Air Conditioning, jumlah massa refrigeran pada isian penuh $\mathrm{HC}$ 134 lebih sedikit dibandingkan dengan R-134a. Untuk R-134a sebesar 420 gram, sedangkan HC-134 sebesar 240 gram. Disamping pemakaian refrigeran yang lebih sedikit, aplikasi HC-134 juga memberikan nilai COP (coeffcient of performance) yang lebih tinggi dibanding dengan R-134a.

Kata kunci: Jenis refrigerasi, efek refrigerasi, kerja kompresi, COP.

\section{Pendahuluan}

\subsection{Latar Belakang}

Karakteristik prestasi masing-masing komponen pembentuk sistem refrigerasi kompresi uap tidak bekerja sendiri, tetapi bergabung dalam satu sistem, Parameter performansi sistem refrigerasi kompresi uap antara lain; kerja kompresi, efek refrigerasi dan COP. Penentuan parameter tersebut dapat dibantu dengan menggunakan sketsa proses pada diagram tekanan enthalpy atau biasa disebut diagram P-h (pressure-enthalpy).

Refrigeran hidrokarbon memiliki beberapa kelebihan seperti ramah lingkungan, yang ditunjukkan dengan nilai Ozon Depleting Potential (ODP) nol, dan GWP yang dapat diabaikan, properti termofisika dan karakteristik perpindahan kalor yang baik, kerapatan fasa uap yang rendah, dan kelarutan yang baik dengan pelumas mineral. 


\subsection{Perumusan dan Batasan Masalah}

Bagaimana pengaruh aplikasi refrigeran hidrokarbon terhadap performansi Mobile Air Conditioning (MAC) ?. Adapun batasan masalah dari penelitian ini yaitu analisa siklus pada kondisi ideal, dan data diperoleh setelah sistem refrigerasi pada keadaan tunak (steady state).

\subsection{Tujuan dan Manfaat Penelitian}

Tujuan dari penelitian ini adalah untuk mengkaji seberapa besar pengaruh performansi setelah dilakukan proses retrofit ke refrigeran hidrokarbon. Adapun manfaatnya yaitu sebagai referensi buat masyarakat untuk beralih ke refrigeran hidrokarbon dilihat dari aspek teknis, ekonomi maupun lingkungan.

\section{Tinjauan Pustaka}

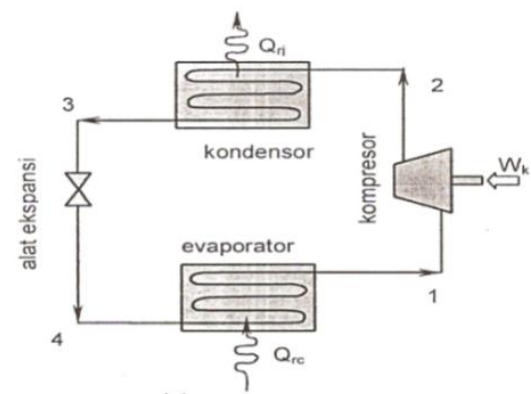

(a)

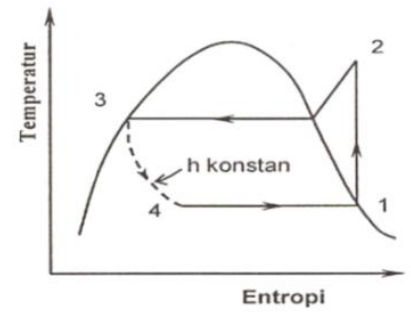

(b)

Gambar 2.1. Siklus kompresi uap standar

(a) Diagram alir proses (b) Diagram temperatur-entropi (T-s)

Sumber: Pasek, 2007.

\subsection{Analisa Kinerja Mesin Refrigerasi Kompresi Uap}

Parameter-parameter prestasi sistem refrigerasi kompresi uap antara lain: efek/dampak refrigerasi, kerja kompresi, kapasitas refrigerasi, dan koefisien performansi (coefficient of performance, COP). Penentuan parameter -parameter tersebut dapat dibantu dengan penggunaan sketsa proses pada diagram

\subsection{Sistem refrigerasi siklus kompresi uap Standar (Teoritis)}

Siklus kompresi uap standar merupakan siklus teoritis, dimana pada siklus tersebut mengasumsikan beberapa proses sebagai berikut:

-1-2 merupakan proses kompresi adiabatic dan reversible, dari uap jenuh menuju ke tekanan kondensor.

- 2-3 merupakan proses pelepasan kalor reversible pada tekanan konstan, menyebabkan penurunan panas lanjut (desuperheating) dan pengembunan refrigerasi.

- 3-4 merupakan proses ekspansi unreversibel pada entalpi konstan, dari fase cair jenuh menuju tekanan evaporator.

-4-1 merupakan proses penambahan kalor reversible pada tekanan konstan yang menyebabkan terjadinya penguapan menuju uap jenuh. tekanan-entalpi. (Stocker, 1996; Pasek, 2004)

Kerja kompresi persatuan massa refrigeran ditentukan oleh perubahan entalpi pada proses 1-2 dan dapat dinyatakan sebagai: (Stocker, 1996)

$$
w=\frac{W}{m}=h_{2}-h_{1}
$$

Dimana: 


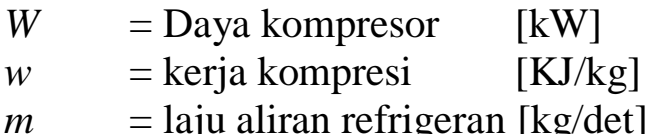

Hubungan tersebut diturunkan dari persamaan energi dalam keadaan tunak, pada proses kompresi adiabatik reversibel dengan perubahan energi kinetik dan energi potensial diabaikan. Perbedaan entalpinya merupakan besaran negatif yang menunjukkan bahwa kerja diberikan kepada sistem.

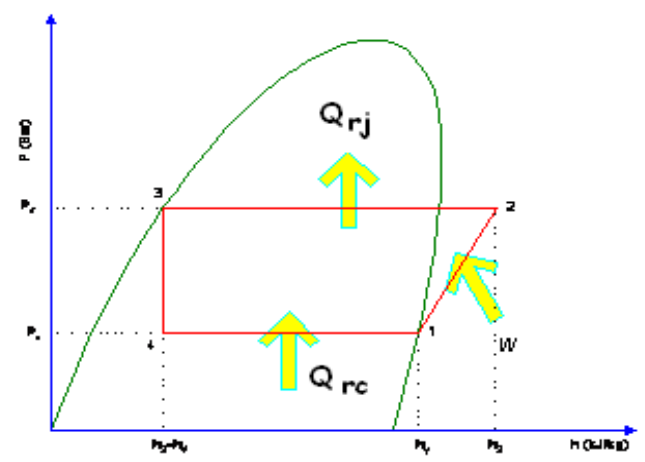

Gambar 2.2. Siklus refrigerasi kompresi uap ideal pada diagram tekanan-entalpi (Ph). Sumber: Herlianika, 2005.

Kalor yang dibuang melalui kondensor dari refrigeran ke lingkungan yang lebih rendah temperaturnya terjadi pada proses $2-3$, yaitu:

$q_{r j}=\frac{Q_{r j}}{m}=h_{2}-h_{3}$

Dimana:

$Q_{r j} \quad=$ Kapasitas Kondensor / pemanasan $\quad[\mathrm{kW}]$

$q_{r j} \quad=$ kalor yang dibuang melalui kondensor $\quad[\mathrm{KJ} / \mathrm{kg}]$

$m \quad=$ laju aliran refrigeran $[\mathrm{kg} / \mathrm{det}]$

Besaran ini bernilai negatif, karena kalor dipindahkan dari sistem refrigerasi ke lingkungan.

Pada proses 3-4 merupakan proses ekspansi refrigeran menuju tekanan evaporator. Proses ini biasanya dimodelkan dengan proses cekik tanpa adanya perpindahan kalor (adiabatik) dan proses berlangsung tak-reversibel,

7. Leak detector (Alat uji kebocoran refrigeran) sehingga diperoleh hubungan: $h_{3}=h_{4}$

Efek refrigerasi $\left(q_{r c}\right)$ adalah kalor yang diterima oleh sistem dari lingkungan melalui evaporator per satuan laju massa refrigeran. Efek refrigerasi merupakan parameter penting, karena merupakan efek yang berguna dan diinginkan dari suatu sistem refrigerasi.

$$
q_{r c}=\frac{Q_{r c}}{m}=h_{1}-h_{4} \ldots \ldots \ldots \ldots \ldots . . .2 .3
$$

Sedangkan kapasitas refrigerasi $\left(Q_{r c}\right)$ merupakan perkalian antara laju massa refrigeran dengan efek refrigerasi.

Dimana:

$$
\begin{array}{ll}
Q_{r c} & =\text { Kapasitas refrigerasi }[\mathrm{kW}] \\
q_{r c} & =\text { efek refrigerasi } \quad[\mathrm{KJ} / \mathrm{kg}] \\
m & =\text { laju aliran refrigeran }[\mathrm{kg} / \mathrm{det}] \\
& \text { Koefisien performansi (COP), }
\end{array}
$$
adalah besarnya energi yang berguna, yaitu efek refrigerasi, dibagi dengan kerja yang diperlukan sistem, yaitu kerja kompresi.

Koefisien Performansi $(\mathrm{COP})=$

$$
\frac{\text { efek refrigerasi }}{\text { kerja kompresi }}=\frac{h_{1-h_{4}}}{h_{2-h_{1}}} \ldots . .2 .4
$$

\section{Metodologi Penelitian}

\subsection{Tempat dan Waktu Penelitian}

Tempat penelitian dilakukan di laboratorium Mesin Pendingin Program Studi Teknik Mesin F(aR.Ri)tas Teknologi Industri Universitas Balikpapan (UNIBA). Waktu penelitian dilaksanakan pada bulan Februari s/d Nopember 2012.

\subsection{Bahan dan Alat}

Adapun perlengkapan dan alat penelitian yang digunakan adalah:

1. Satu unit uji sistim refrigrasi $A C$ Mobil yang sudah dimodifikasi.

2. Pompa vakum

3. Gauge manifold

4. Termometer (Digital)

5. Timbangan refrigeran (Digital)

6. Refrigeran R-134a merk Klea dan refrigeran hidrokarbon $(\mathrm{HC})$ merk

8. Multimeter (Gigital)

9. Peralatan workshop 


\subsection{Langkah-langkah Penelitian}

Langkah-langkah penelitian adalah sebagai berikut:

1. Menyiapkan peralatan uji sistim refrigerasi dan perlengkapan lainnya

2. Sistim divakum terlebih dahulu dengan menggunakan pompa vakum

3. Melakukan pengisian dengan refrigeran R-134a sampai terisi penuh

4. Menghidupkan alat uji sampai dengan kondisi konstan

5. Mencatat hasil pengukuran temperature dan tekanan $\mathrm{T}_{1}, \mathrm{~T}_{2}, \mathrm{~T}_{3}$, $\mathrm{T}_{4}, \mathrm{P}_{1}, \mathrm{P}_{2}$

6. Mengulang semua langkah dengan menggunakan refrigeran MC-134

\subsection{Variabel Penelitian}

Variabel-variabel dalam penelitian:

1. Variabel bebas, yang meliputi:

- Jenis Refrigran, R-134a dan

Hidrokarbon MC-22
- Interrval waktu

[menit]

2. Variabel terikat

- Efek refrigerasi

$[\mathrm{KJ} / \mathrm{kg}]$

- Kerja Kompresor

$[\mathrm{KJ} / \mathrm{kg}]$

- COP (coeffcient of performance)

3. Variabel Kontrol, yang meliputi penggunaan:

- Temperatur ruang uji $29-30{ }^{\circ} \mathrm{C}$.

- Kelembaban ruang uji $85 \pm 1{ }^{\circ} \mathrm{C}$ (relatif)

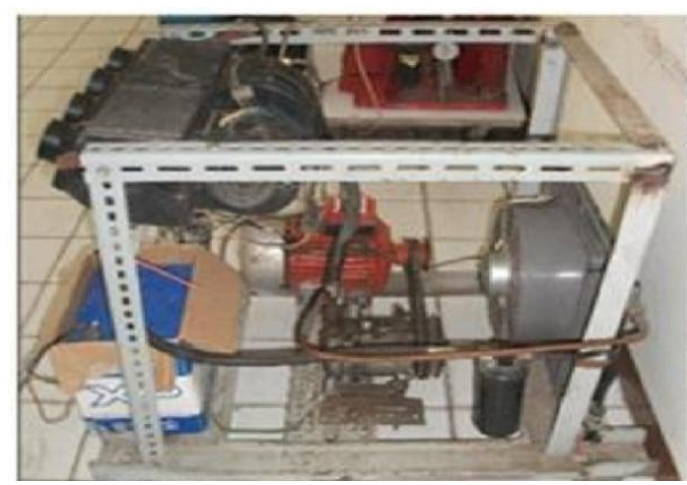

Gambar 3.1.

Alat uji Mobile Air Conditioning(MA

\section{Hasil dan Pembahasan}

4.1. Spesifikasi alat uji dan data pengujian siklus ideal

Spesifikasi alat uji

Tipe alat uji

Jenis Kompressor

: Mobile Air Conditioning (MAC)

: Tipe torak

Tabel 4.1 Hasil pengujian dan pengolahan data R-134a pada siklus ideal

\begin{tabular}{|c|c|c|c|c|c|c|c|c|c|c|c|c|c|}
\hline \multirow{2}{*}{$\begin{array}{c}\text { Menit } \\
\text { ke- }\end{array}$} & \multicolumn{4}{|c|}{ Temperatur $\left({ }^{\circ} \mathrm{C}\right)$} & \multicolumn{2}{|c|}{ Tekanan (bar) } & \multicolumn{3}{|c|}{ Enthalpy } & \multirow{2}{*}{$\begin{array}{c}(\mathrm{w})= \\
\text { kerja } \\
\text { kompresi } \\
h_{2}-h_{1}\end{array}$} & \multirow{2}{*}{$\begin{array}{c}\left(Q_{r i}\right)=\text { Kalor } \\
\text { kel. } \\
\text { Kondensor } \\
h_{2}-h_{3}\end{array}$} & \multirow{2}{*}{$\left(\begin{array}{c}\left(Q_{r c}\right)=\text { efek } \\
\text { refrigerasi } \\
h_{1}-h_{4}\end{array}\right.$} & \multirow{2}{*}{$\begin{array}{c}\text { COP } \\
\left(h_{1}-h_{4}\right) / \\
\left(h_{2}-h_{1}\right)\end{array}$} \\
\hline & $\mathrm{T} 1$ & T2 & T3 & T4 & $P 1=P 4$ & $P 2=p 3$ & $h_{1}$ & $h_{2}$ & $h_{3}=h_{4}$ & & & & \\
\hline 5 & 5 & 53 & 33 & -22 & 1.2 & 8.3 & 384.054 & 423.916 & 245.819 & 39.862 & 178.097 & 138.235 & 3.47 \\
\hline 10 & -2 & 67 & 36 & -20 & 1.3 & 9.1 & 385.279 & 425.125 & 250.22 & 39.846 & 174.905 & 135.059 & 3.39 \\
\hline 15 & -6 & 67 & 34 & -22 & 1.2 & 8.6 & 384.054 & 424.517 & 247.281 & 40.463 & 177.236 & 136.773 & 3.38 \\
\hline 20 & -8 & 68 & 35 & -22 & 1.2 & 8.8 & 384.054 & 425.114 & 248.748 & 41.06 & 176.366 & 135.306 & 3.30 \\
\hline 25 & -7 & 69 & 35 & -23 & 1.1 & 8.8 & 383.44 & 425.415 & 248.748 & 41.975 & 176.667 & 134.692 & 3.21 \\
\hline
\end{tabular}


Tabel 4.2 Hasil pengujian dan pengolahan data refrigeran hidrokarbon MC-134 pada siklus ideal

\begin{tabular}{|c|c|c|c|c|c|c|c|c|c|c|c|c|c|}
\hline \multirow{2}{*}{$\begin{array}{c}\text { Menit } \\
\text { ke- }\end{array}$} & \multicolumn{4}{|c|}{ Temperatur $\left({ }^{\circ} \mathrm{C}\right)$} & \multicolumn{2}{|c|}{ Tekanan (bar) } & \multicolumn{3}{|c|}{ Enthalpy } & \multirow{2}{*}{$\begin{array}{c}(w)= \\
\text { kerja } \\
\text { kompresi } \\
h_{2}-h_{1}\end{array}$} & \multirow{2}{*}{$\begin{array}{c}\left(Q_{\mathrm{rj}}\right)=\text { Kalor } \\
\text { kel. } \\
\text { Kondensor } \\
h_{2}-h_{3}\end{array}$} & \multirow{2}{*}{$\left(\begin{array}{c}\left(Q_{r c}\right)=\text { efek } \\
\text { refrigerasi } \\
h_{1}-h_{4}\end{array}\right.$} & \multirow{2}{*}{$\begin{array}{c}\text { COP } \\
\left(h_{1}-h_{4}\right) / \\
\left(h_{2}-h_{1)}\right.\end{array}$} \\
\hline & $\mathrm{T} 1$ & T2 & T3 & T4 & $P 1=P 4$ & $P 2=p 3$ & $h_{1}$ & $h_{2}$ & $h_{3}=h_{4}$ & & & & \\
\hline 5 & 8 & 56 & 36 & -20 & 1.5 & 9.2 & 546.8 & 613.76 & 291.82 & 66.96 & 321.94 & 254.98 & 3.81 \\
\hline 10 & 0 & 64 & 39 & -21 & 1.5 & 9.2 & 545.52 & 616.85 & 299.98 & 71.33 & 316.87 & 245.54 & 3.44 \\
\hline 15 & 3 & 68 & 33 & -20 & 1.6 & 9.6 & 549.36 & 617.44 & 302.70 & 68.08 & 314.74 & 246.66 & 3.62 \\
\hline 20 & 3 & 69 & 39 & -19 & 1.6 & 9.9 & 548.08 & 616.59 & 299.98 & 68.51 & 316.61 & 248.10 & 3.62 \\
\hline 25 & 2 & 70 & 41 & -18 & 1.6 & 9.9 & 549.36 & 618.40 & 305.46 & 69.04 & 312.94 & 243.90 & 3.53 \\
\hline
\end{tabular}

Pada pengujian refrigeran $\mathrm{R}-134 \mathrm{a}$ jumlah massa refrigeran yang dimasukan ke dalam alat uji sistem MAC dalam keadaan penuh. Sebagai acuan kalau isian sudah penuh pada indikator sigh glass berwarna bening dan tidak terlihat ada gelembung udara. Setelah proses pengambilan data selesai dilakukan, barulah kita dapat menghitung nilai dari efek refrigerasi, kerja kompresi dan nilai COP dari kedua jenis refrigeran tersebut.

\subsection{Perbandingan efek refrigerasi}

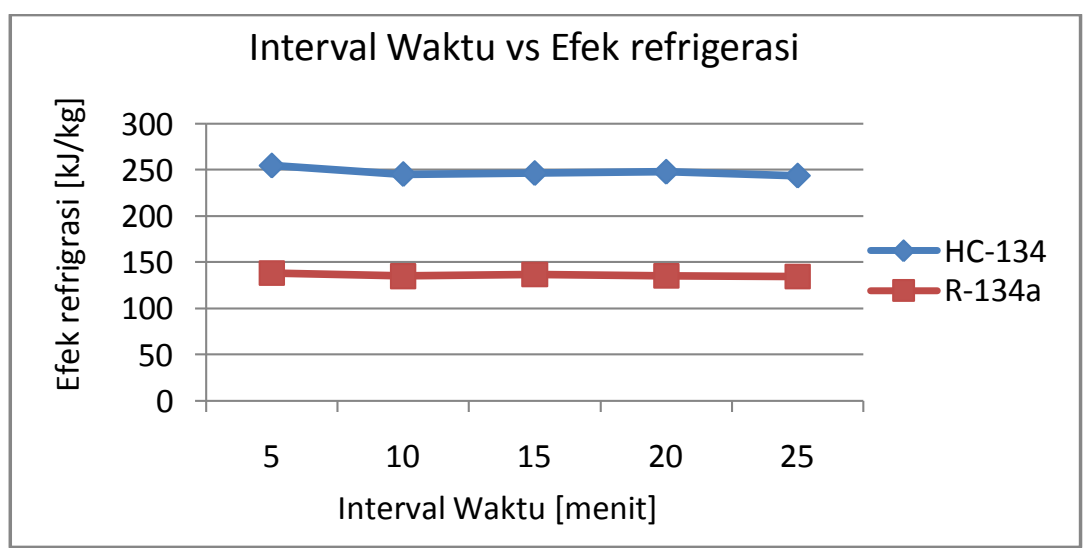

Gambar 4.1. Grafik Perbandingan Interval waktu vs Efek refrigerasi

Peningkatan efek refrigrasi dipengaruhi oleh kemampuan evaporator menyerap kalor dari luar untuk menguapkanya. Selisih nilai efek refrigrasi yang cukup besar antara refrigran hidrokarbon Musicool MC-134 dengan R-134a memberikan dampak yang sangat besar bagi peningkatan nilai COP. 


\subsection{Perbandingan kerja kompresi pada kompresor}

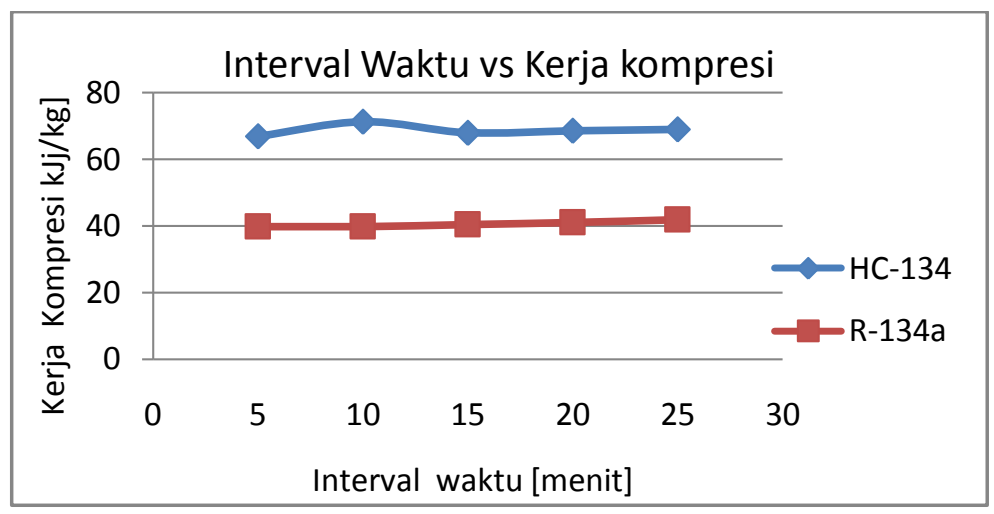

Gambar 4.2. Grafik Perbandingan Interval waktu vs Kerja kompresi

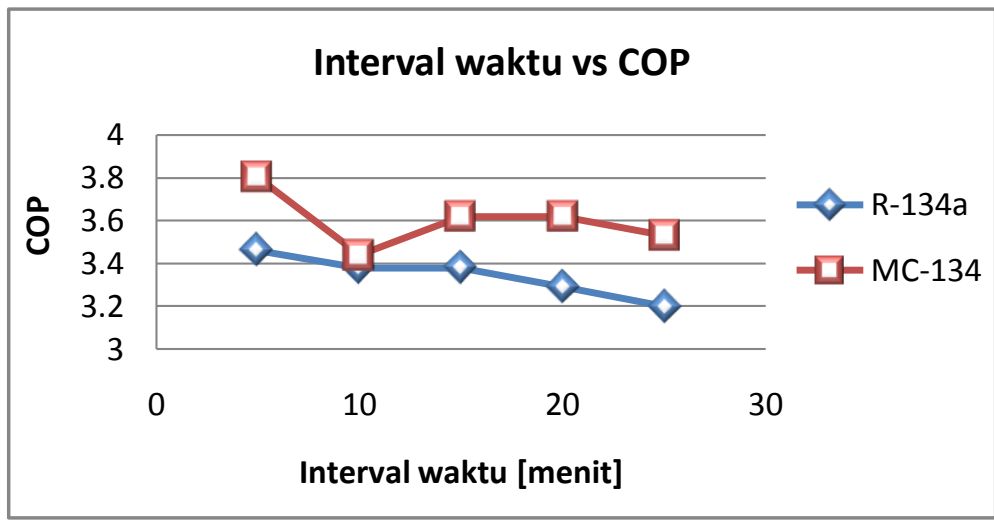

Gambar 4.3. Grafik Perbandingan Interval waktu vs COP

Koefisien performasi (COP) adalah bentuk penilaian dari suatu mesin refrigerasi, semakin besar nilai COP menunjukkan bahwa kerja mesin tersebut semakin baik. Dari grafik di atas disimpulkan bahwa aplikasi refrigeran MC-134 hidrokarbon akan memberikan nilai COP yang lebih tinggi dibandingkan dengan R-134a.

\section{Kesimpulan}

Kesimpulan yang diperoleh dari hasil penelitian adalah sebagai berikut:

1. Dari hasil data pengujian pada alat uji Mobile Air Conditioning (MAC), jumlah massa refrigeran pada isian penuh hidrokarbon MC-134 lebih sedikit dibandingkan dengan $\mathrm{R}-134 \mathrm{a}$. Untuk R-134a sebesar 420 gram, sedangkan hidrokarbon MC-134 sebesar 240 gram.
2. Nilai COP yang dihasilkan dari aplikasi refrigeran hidrokarbon MC-134 lebih tinggi dibanding dengan R-134a.

3. Interval waktu dipergunakan untuk mengetahui trend nilai COP tetap stabil.

\section{Daftar Pustaka}

1. A. R. Trott and T.C. Welch, 2000, Refrigeration \& Air-Conditioning (Third edition), ButterworthHeinemann, Oxford.

2. Arismunandar, W dan Saito, H, 2002, Penyegaran Udara, Cetakan ke-6, PT. Pradnya, Paramita, Jakarta.

3. Daly S. 2006: Automotive Air Conditioning And Climate Control Systems, Butterworth-Heinemann, Oxford.

4. Dincer, I., 2003, Refrigeration System and Application, Wiley, England. 
5. Herlianika, H, 2005, Eksperimen Dengan Alat Peraga Refrigerasi Dasar, Butterworth-Heinemann, Oxford.

6. Moran J. Michael \& Shapiro, N, Howard, Fundamentals of Engineering Thermodinamics. John Wiley \& Son Ltd. England, $5^{\text {th }}$ Edition.
7. Pasek, A.D., 2007, Retrofit Sistim Refrigerasi Dan Pengkondisian Udara Ramah Lingkungan, Pusat Pendidikan dan Pelatihan Kementerian Lingkungan Hidup, Jakarta.

8. Stocker, W.F., 1996, Refrigerasi dan Pengkondisian Udara, Erlangga, Jakarta. 